\title{
ANALISIS PERGERAKAN POLUTAN TRIKLOROETILEN DALAM MEDIA BERPORI MENGGUNAKAN SENTRIFUG GEOTEKNIK (Analysis of Trichloroethylene Pollutant Migration in Porous Media Using Geotechnical Centrifuge)
}

\author{
Muchlis $^{1^{*}}$ dan Muhammad Mukhlisin² \\ ${ }^{1}$ Program studi Teknik Geologi, Fakultas Teknologi Mineral, Institut Sains dan Teknologi \\ AKPRIND Yogyakarta. Jl. Kalisahak no. 28 Komplek Balapan, Yogyakarta 55222. \\ ${ }^{2}$ Jurusan Teknik Sipil, Politeknik Negeri Semarang, Jl. Prof Sudarto SH., \\ Tembalang, Semarang 50275.
}

*Penulis korespondensi. Tel: 0857-4360-9606. Email: muchlis_idham@yahoo.com.

Diterima: 2 April 2015

Disetujui: 16 November 2015

\begin{abstract}
Abstrak
Trikloroetilen (TCE) adalah pelarut organik yang sering digunakan dalam proses industri. TCE adalah salah satu contoh dari Non Aqueous Phase Liquid (NAPL) yang sudah banyak mencemari tanah dan air tanah. Tujuan penelitian ini adalah untuk mengetahui sifat-sifat pergerakan TCE dalam berbagai jenis tanah yang berbeda, mengkaji sifat-sifat pergerakan TCE dalam tanah dengan menggunakan kecepatan 1 dan 25 Gravitasi, dan mengetahui faktor-faktor yang mempengaruhi pergerakan TCE dalam tanah. Sifat pergerakan TCE dalam tanah riolit dan granit adalah TCE akan masuk langsung secara vertikal dan horizontal dalam tanah hingga ke dasar tanah. Pergerakan TCE akan terhambat pada tanah yang banyak mengandung partikel berukuran kecil. Pergerakan TCE secara vertikal pada gaya 1G dan 25G dalam tanah granit adalah paling cepat berbanding dalam tanah riolit. Pergerakan TCE dalam tanah kering dipengaruhi oleh sifat tanah terutama ukuran butir dan Kapasitas Pertukaran Kation (KPK).
\end{abstract}

Kata kunci: pergerakan polutan, sentifug geoteknik, tanah granit, tanah riolit, trikloroetilen.

\begin{abstract}
Tricholoroethylene (TCE) is an organic solvent used in many industrial processes. TCE is one of Non-Aqueous Phase Liquid (NAPL) which has already contaminated soil and groundwater. The objectives of this study are to determine the migration of TCE in rhyolite and granite soil, to determine the migration of TCE in soil using 1 and 25 Gravity (G) force, and to determine the migration of TCE influencing factors in the soil. The characteristics of TCE migration in rhyolite and granite soil will migrate vertically and laterally to the bottom of the ground. The migration will be retarded in small particle size of soil. The fastest migration of TCE at $1 G$ and $25 G$ was found in the granite soil. The migration of TCE in dry soil is affected by properties of soil particularly particle size and cation exchange capacity.
\end{abstract}

Keywords: pollutant migration, geotechnical centrifuge, granite, rhyolite, trichloroethylene.

\section{PENDAHULUAN}

Pencemaran tanah dan air tanah yang disebabkan oleh Non Aqueous Phase Liquid (NAPL) sudah menjadi perhatian masyarakat. Sleep dkk. (2003) melaporkan bahwa NAPL jenis trikloroetilen (TCE) sudah digunakan secara luas sebagai pelarut sejak tahun 1940-an dan menjadi pencemar pada tanah dan air tanah. TCE merupakan senyawa berbahaya karena bersifat persisten dan bertoksik tinggi (Ma dkk., 2007). Peneliti dari Parkinson Institut menemukan bahwa manusia yang terpapar dengan TCE berkemungkinan terkena penyakit parkinson hampir enam kali lipat berbanding yang tidak (Anonim, 2010).

Banyak metode yang dapat digunakan untuk memulihkan tanah dan air tanah yang tercemar NAPL (Anonim, 2001), akan tetapi mengidentifikasi proses pergerakan polutan adalah salah satu langkah pertama dalam usaha menilai dan memulihkan pencemaran tanah (Wilson dan Clarke, 2004). Oleh karena itu sifat pergerakan NAPL perlu dikaji agar pemulihan berjalan dengan efektif dan efisien (Barth dkk., 2003).

Penelitian tentang pergerakan NAPL sudah banyak dilakukan sejak lama (Hu dkk., 2006). Pada dasarnya, pergerakan NAPL dalam tanah bisa diperkirakan dengan menggunakan permodelan matematik yaitu dengan metoda analitikal atau numerikal. Permodelan matematik didasarkan kepada data yang diperoleh dari uji lapangan atau uji kolom di laboratorium. Kedua uji ini mempunyai keterbatasan yaitu untuk mendapatkan hasil memerlukan waktu yang lama (Kumar, 2006). Oleh karena itu dibutuhkan alat sehingga untuk 
mendapatkan hasil pergerakan NAPL dibutuhkan waktu yang relatif singkat.

Banyak peneliti memakai sentrifug geoteknik sebagai permodelan fisikal pada penelitian pergerakan NAPL (Soga dkk., 2003). Penelitian dengan menggunakan sentrifug geoteknik dapat mempersingkat waktu uji (Kumar, 2006). Prinsip dasar penggunaan sentrifug geoteknik adalah kemampuannya untuk meningkatkan kecepatan gravitasi dari 1 menjadi $\mathrm{N}$ gravitasi (NG). Penambahan kecepatan gravitasi menjadi NG menyebabkan NAPL bergerak $\mathrm{N}^{2}$ lebih cepat (Hu dkk., 2006), hal ini dapat digunakan untuk memperkirakan pergerakan NAPL pada masa yang akan datang (Lo dkk., 2004). Keuntungan lain dari alat ini adalaha kemampuannya untuk memodelkan sistem alamiah yang komplek dalam keadaan laboratorium yang terkontrol (Kumar, 2006), jumlah tanah yang digunakan lebih sedikit, lebih murah dan cepat mendapatkan hasil (Soga dkk., 2003). Dengan menggunakan sentrifug geoteknik maka penelitian Setyoningrum dkk. (2014) dapat dikembangkan lagi misal memperkirakan pergerakan unsur Cadmium (Cd) di Tempat Pembuangan Akhir Sampah (TPAS) Piyungan dalam jangka waktu tertentu.

Selain sentrifug geoteknik, banyak juga peneliti yang menggunakan tangki sebagai alat permodelan fisikal dua dimensi untuk melihat pergerakan NAPL (Ca’piro dkk., 2007; Luciano dkk., 2010). Penelitian dengan memakai tangki digunakan untuk mengetahui pergerakan NAPL pada kecepatan satu gravitasi. Penelitian memakai tangki dapat digunakan untuk mengetahui pergerakan NAPL secara visual ataupun dengan pengukuran secara kuantitatif dengan cara menambahkan sensor pada tangki tersebut.

Perumusan masalah penelitian adalah bagaimana sifat dan faktor-faktor yang mempengaruhi pergerakan polutan TCE dalam tanah riolit dan granit pada kecepatan 1Gravitasi (G) dan 25G. Penelitian mempunyai tiga tujuan yaitu mengetahui sifat-sifat pergerakan TCE dalam berbagai jenis tanah yang berbeda, mengkaji sifatsifat pergerakan TCE dalam tanah dengan menggunakan kecepatan $1 \mathrm{G}$ dan 25G, dan mengetahui faktor-faktor yang mempengaruhi pergerakan TCE dalam tanah.

Penelitian menggunakan kecepatan $1 \mathrm{G}$ dan 25G. Kecepatan 1G didapat secara alamiah tanpa alat bantu penambah kecepatan. Kecepatan 25G didapat dengan alat bantu yaitu sentrifug geoteknik. Penelitian menggunakan sentrifug geoteknik yang baru selesai dibuat. Pembuatan sentrifug dilakukan sendiri dengan tidak melibatkan pihak pabrik. Kecepatan maksimum alat tersebut adalah 50G. Penelitian menggunakan separuh dari kecepatan maksimum sentrifug karena alasan keselamatan dalam pelaksanaannya.

\section{METODE PENELITIAN}

Metode yang digunakan meliputi penyediaan sampel tanah, analisis sampel tanah untuk mengetahui sifat tanah, dan analisis visual pergerakan TCE dengan menggunakan tangki untuk kecepatan 1G dan menggunakan sentrifug geoteknik untuk kecepatan 25G.

\section{Penyediaan Sampel Tanah}

Tanah yang dipakai adalah tanah residu granit dan riolit. Tanah granit diambil dari kawasan Braga, Semenyih, Malaysia dengan posisi $02^{\circ} 56.299^{\prime} \mathrm{U}$ dan 10155.327'T sedangkan tanah riolit dari Lanchang, Pahang, Malaysia dengan posisi $03^{\circ} 29.529^{\prime} U$ dan $102^{\circ} 12.841^{\prime} T$. Sebelum persampelan dilakukan, tanah permukaan dibuang terlebih dahulu. Tanah yang diambil kemudian dikeringkan dalam oven dengan suhu $105{ }^{\circ} \mathrm{C}$ selama 24 jam, lalu diayak menggunakan ayakan mesh no 30. Tanah yang sudah diayak digunakan untuk uji sifat tanah dan uji pergerakan TCE.

\section{Analisis Sifat-sifat Tanah}

Tanah diuji dengan beberapa sifat yaitu $\mathrm{pH}$, taburan ukuran butir (particle size distribution), batas-batas Atterberg, kandungan mineral lempung, kapasitas pertukaran kation (cation exchange capacity) dan luas permukaan spesifik (specific surface area). Sifat taburan ukuran butir dan batasbatas Atterberg menggunakan metode dari US Army Corps of Engineers (Anonim, 2011). Kandungan mineral lempung menggunakan metode $X$ Ray Diffraction (XRD. Sifat kapasitas pertukaran kation dan luas permukaan spesifik menggunakan metode dari Geotechnical Research Center (GRC) (Anonim, 1985).

\section{Analisis Visual Pergerakan TCE}

Uji pergerakan bertujuan untuk mengetahui pergerakan TCE dalam tanah granit dan riolit secara visual pada kecepatan 1G dan 25G. Uji pergerakan pada kecepatan $1 \mathrm{G}$ menggunakan tangki, sedangkan 25G menggunakan sentrifug geoteknik. Pergerakan yang ingin diketahui adalah pergerakan secara vertikal dan horizontal. Pergerakan secara vertikal adalah pergerakan TCE searah dengan tinggi kotak sampel manakala pergerakan secara horizontal adalah pergerakan searah dengan panjang kotak sampel.

Tangki yang dipakai dibuat dari kaca dan berukuran panjang $29 \mathrm{~cm}$, tinggi $20 \mathrm{~cm}$ dan lebar 4,5 $\mathrm{cm}$. Kotak sampel sentrifug geoteknik berukuran panjang $29 \mathrm{~cm}$, tinggi $20 \mathrm{~cm}$ dan lebar $12 \mathrm{~cm}$ dan 
dibuat dari aluminium dengan bagian depan dari perspek yang tembus cahaya agar pergerakan TCE dapat dilihat. Pada kotak sampel diberi spon sedemikian rupa sehingga tanah sampel mempunyai lebar 4,5 cm. Hal ini dibuat agar volume tanah pada kotak sampel sama dengan pada tangki. Gambar 1 menunjukkan tangki dan kotak sampel yang dipakai.

Tangki dan kotak sampel diisi dengan media tanah. Sebanyak $40 \mathrm{~mL}$ TCE yang diwarnakan merah menggunakan Sudan $\mathrm{V}$ disuntikkan pada bagian atas media dan pergerakannya diperhatikan. Pergerakan TCE direkam dengan menggunakan kamera.

\section{Uji Pergerakan dengan Menggunakan Tangki (1G)}

Penyuntikan TCE dilakukan dengan menggunakan corong. Pergerakan TCE setelah disuntik direkam dengan menggunakan kamera secara manual (bukan otomatis) dimana Gambar diambil dari depan tangki setiap 10 menit. Ujian pergerakan TCE dengan menggunakan tangki dilakukan selama 90 menit.

\section{Uji dengan menggunakan sentrifug geoteknik (25G)}

TCE dimasukkan dalam botol polutan, kemudian kotak sampel diputar sampai kecepatan 25G (210 RPM). Pada kecepatan 25G, botol polutan dibuka dengan menggunakan remote control sehingga TCE keluar dan bergerak pada tanah di kotak sampel. Kamera akan merekam pergerakan yang terjadi pada kotak sampel secara otomatis dengan perangkat lunak VZOR/DV3116 yang dimasukkan dalam komputer. Ujian pergerakan TCE dengan menggunakan sentrifug geoteknik dilakukan selama 1 menit.

Hasil ujian pergerakan TCE kemudian di gambar dengan perangkat lunak Corel Draw. Pergerakan TCE dengan kecepatan 1G, yang di gambar adalah foto hasil rekaman tiap 10 menit, sedangkan pada ujian menggunakan kecepatan 25G adalah pada detik pertama sampai 10 , detik ke- 30 dan detik ke 60. Kecepatan pergerakan setelah TCE mencapai dasar atau ujung tangki dihitung kosong karena setelah mencapai dasar atau ujung, panjang pergerakan sudah mencapai titik maksimal.

Kecepatan pergerakan dihitung mengikut persamaan (1):

$$
\mathrm{v}=\frac{d}{t}
$$

dimana:

$\mathrm{v}=$ kecepatan $(\mathrm{cm} /$ detik atau $\mathrm{cm} /$ menit$)$

$\mathrm{d}=$ jarak pergerakan terpanjang $(\mathrm{cm})$

$\mathrm{t}=$ waktu (detik atau menit).

\section{Sentrifug geoteknik}

Sentrifug yang digunakan adalah sentrifug geoteknik Universiti Kebangsaan Malaysia (UKM). Pembuatan sentrifug jenis beam di UKM dimulai

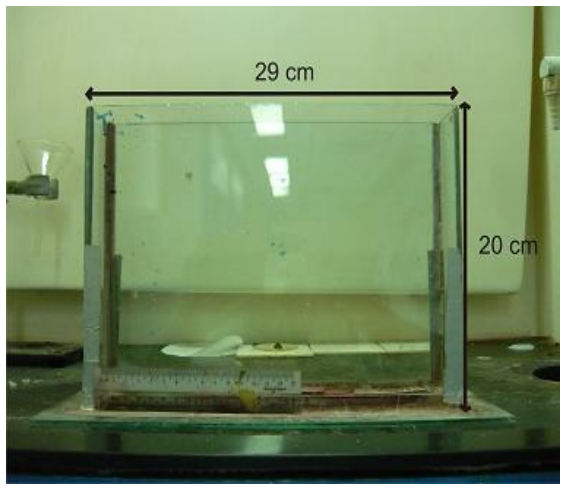

(a)

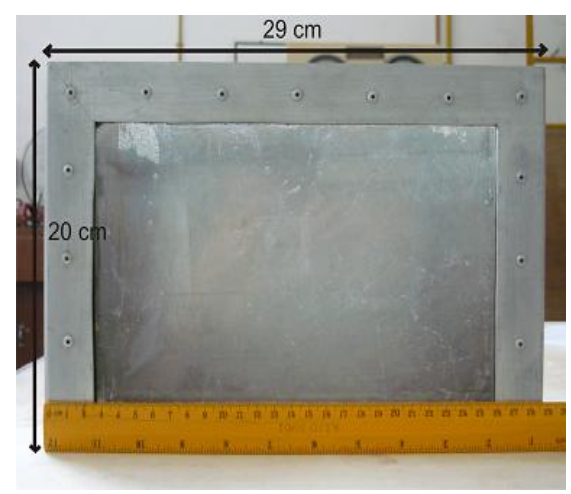

(b)

Gambar 1. Gambar (a) tangki dan (b) kotak sampel.

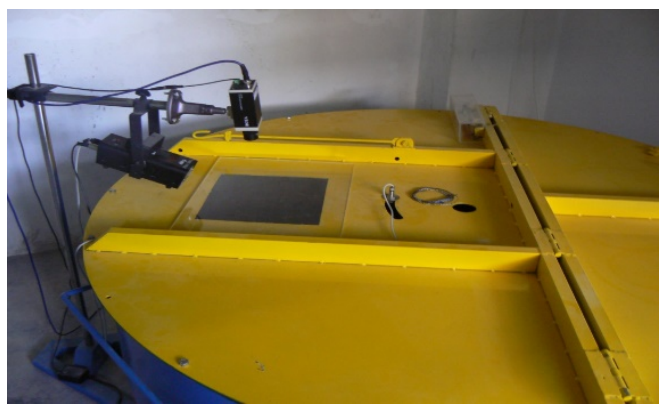

Gambar 2. Sentrifug geoteknik UKM. 
Tabel 1. Hasil ujian sifat-sifat sampel media.

\begin{tabular}{lcc}
\hline \multicolumn{1}{c}{ Sifat fisik dan mineralogi } & Tanah granit $(\mathrm{n}=5)$ & Tanah riolit $(\mathrm{n}=5)$ \\
\hline $\mathrm{pH}$ & $4,8-5,5$ & $5,1-5,2$ \\
Lempung(\%) & $18-26$ & $13,47-18$ \\
Lanau(\%) & $14-19$ & $72,5-75,5$ \\
Pasir(\%) & $55-63$ & $8-11$ \\
LL(\%) & $72-80$ & $33-36$ \\
PL(\%) & $32-41$ & $18-24$ \\
PI(\%) & $35-41$ & $11-17$ \\
KPK(meq/100g) & $0,6-0,9$ & $2,7-11$ \\
LPS(m²/g) & $31,2-64,4$ & $26-31$ \\
Mineralogi lempung & K, G, M & K, Q, Mu \\
\hline
\end{tabular}

Keterangan:

$\mathrm{LL}=$ Liquid Limit, $\mathrm{PL}=$ Plastic Limit, $\mathrm{PI}=$ Indek Keplastikan, $\mathrm{I}=$ Mineral ilit, $\mathrm{K}=$ Mineral kaolinit, G= Mineral geothit, Q= Mineral kuarza, Mu= Mineral muskovit, KPK= Kapasitas Pertukaran Kation, LPS=Luas Permukaan Spesifik.

pada awal tahun 2007 dan berakhir pada 2009. Pembuatan sentrifug dilakukan di dalam UKM dimana disain dibuat berdasar pada hasil pembacaan dan pengamatan terhadap sentrifug geoteknik yang telah ada. Sentrifug geoteknik ini termasuk katagori kecil dengan jejari lengan efektif adalah 0.5 meter. Komponen yang ada adalah sederhana tetapi sangat mungkin untuk ditingkatkan. Kapasitas maksimal tanah pada kotak sampel adalah $6 \mathrm{~kg}$ dengan kecepatan maksimal 50 G. Bagian-bagian utama sentrifug geoteknik UKM adakah motor, badan, lengan, kotak sampel. Sentrifug geoteknik UKM ditunjukkan oleh Gambar 2

\section{HASIL DAN PEMBAHASAN}

\section{Hasil uji sifat fisik dan mineralogi media}

Pergerakan polutan dipengaruhi oleh sifat media tanah yang dilaluinya (Zhang dkk., 2008). Oleh itu sifat-sifat tanah granit dan riolit perlu diketahui. Sifat fisik dan mineralogi sampel tanah dapat dilihat pada Tabel 1.

Pada Tabel 1 terlihat bahwa tanah granit mempunyai nilai kandungan pasir lebih tinggi berbanding riolit. Nilai LL, PL, PI dan LPS tanah granit juga lebih tinggi. Kandungan lempung, lanau tanah riolit lebih banyak berbanding granit. Nilai KPK tanah riolit lebih tinggi berbanding granit.

Plaster (2009) mengatakan bahwa ukuran butir tanah berpengaruh terhadap beberapa sifat tanah diantaranya adalah kapasitas memegang air dan pengudaraan (aeration). Ukuran butir tanah juga berpengaruh terhadap dua sifat tanah yang penting yaitu luas permukaan spesifik dan jumlah ruang antar butir tanah. Tanah yang berukuran butir kecil mempunyai jumlah ruang antar butir yang banyak dan keluasan permukaan spesifik yang lebih besar dibanding tanah berukuran besar. Tekanan kapilari yang lebih besar akan didapat pada tanah yang mempunyai ukuran butir kecil berbanding yang besar.

\section{Hasil pergerakan TCE di media dengan kecepatan 1G dan 25G}

\section{Pada media tanah granit}

Pergerakan dan kecepatan TCE dalam tanah granit pada kecepatan 1G dan 25G ditunjukkan oleh Gambar 3. TCE akan bergerak secara vertikal dan horizontal setelah disuntikan dalam tanah granit. Pergerakan pada kecepatan 1G, di menit ke sepuluh kecepatan vertikal dan horizontal TCE masingmasing adalah 0,45 dan 1,10 cm/menit. Kecepatan TCE semakin menurun pada menit-menit selanjutnya dan pada menit ke-90 kecepatan vertikal dan horizontal masing-masing adalah 0,05 dan 0,13 $\mathrm{cm} /$ menit. Pada menit ke-90 panjang maksimal pergerakan TCE secara vertikal adalah 4,80 cm dan secara horizontal $11,40 \mathrm{~cm}$.

Pergerakan pada kecepatan 25G, setelah disuntikan, TCE akan bergerak secara vertikal dan horizontal di mana pada awalnya kecepatan pergerakan secara horizontal lebih besar berbanding secara vertikal. Pada detik kesatu kecepatan secara vertikal adalah 3,30 $\mathrm{cm} /$ detik dengan kecepatan horizontal 9,00 cm/detik. Pada masa berikutnya kecepatan secara vertikal mendekati kecepatan horizontal. Pada 30 detik kecepatan vertikal dan horizontal masing-masing adalah 0,29 dan 0,40 $\mathrm{cm} /$ detik dan pada 60 detik adalah 0,15 dan 0,20 $\mathrm{cm} /$ detik. Hingga 60 detik, pergerakan secara vertikal TCE belum mencapai dasar tanah.

\section{Pada media tanah riolit}

Pergerakan dan kecepatan TCE dalam tanah riolit kecepatan 1G dan 25G ditunjukkan dalam Gambar 4. Pada kecepatan 1G, TCE akan bergerak secara vertikal dan horizontal setelah disuntikan dalam tanah. Pada 10 menit kecepatan vertikal dan horizontal masing-masing adalah 0,28 dan 2,52 $\mathrm{cm} /$ menit. Pergerakan TCE secara horizontal dari 10 hingga 90 menit tidak ada perubahan yang cukup 

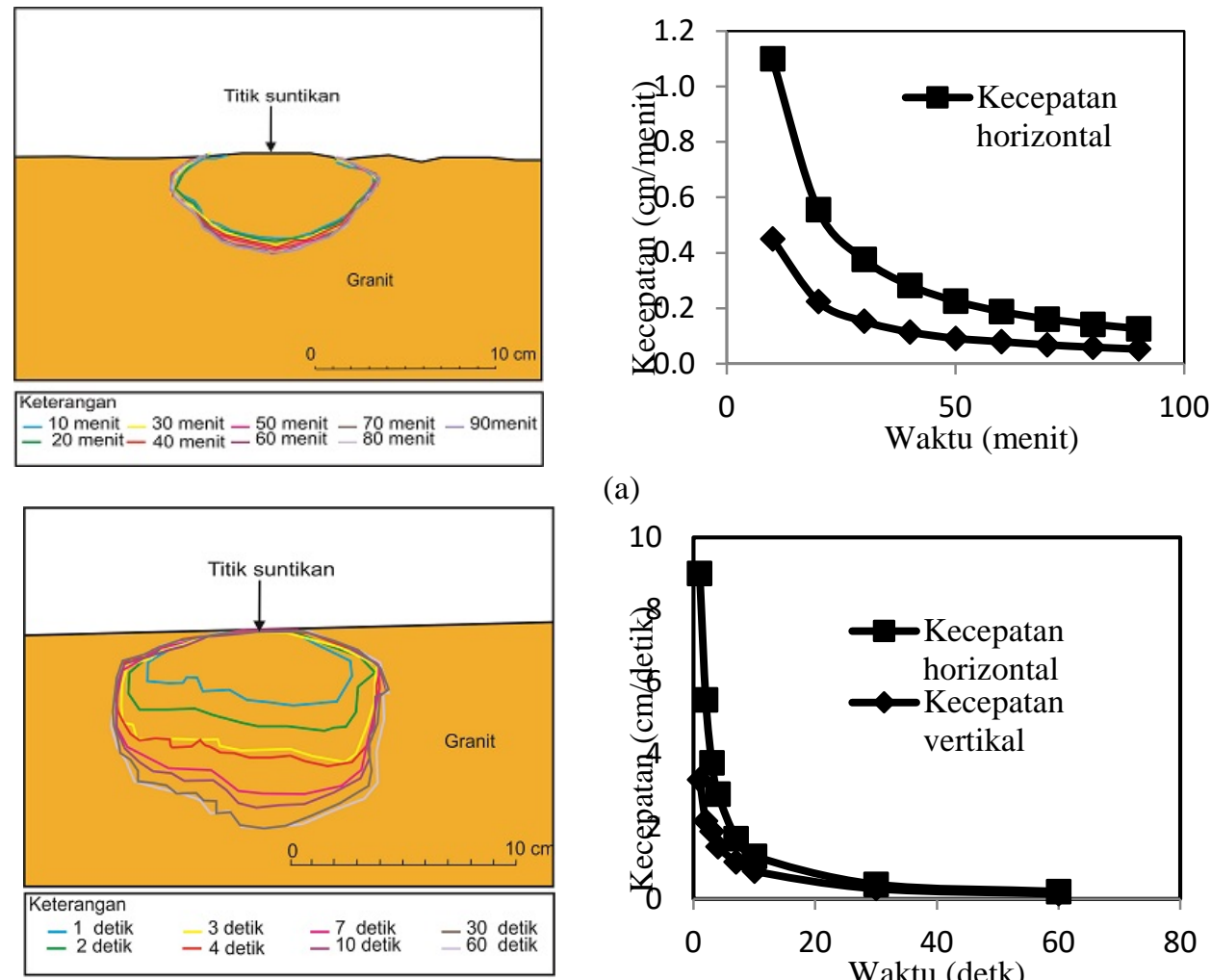

(a)

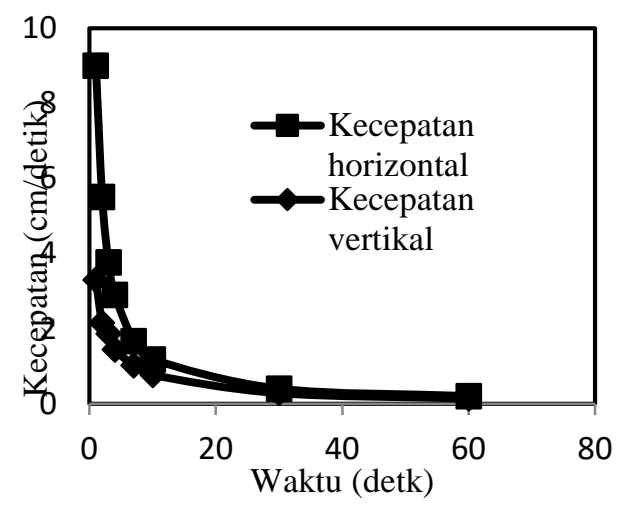

(b)

Gambar 3. Pergerakan TCE dalam tanah granit pada kecepatan (a) 1G dan (b) 25G.
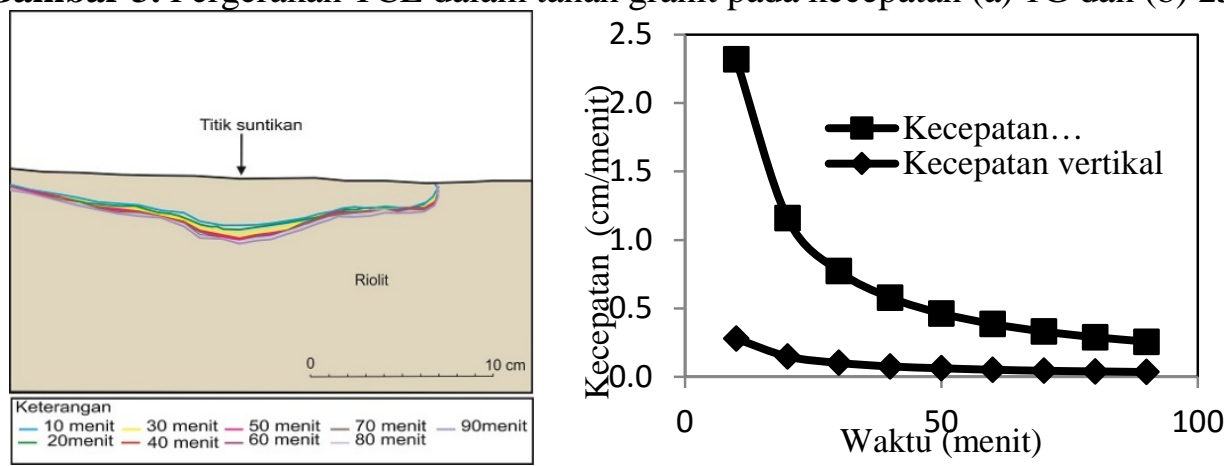

(a)
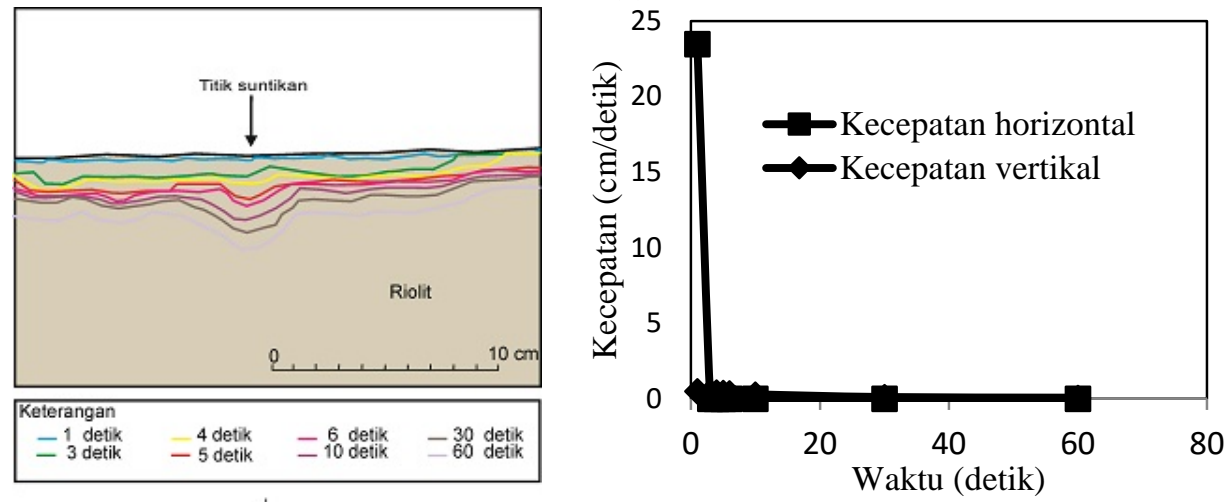

(b)

Gambar 4. Pergerakan TCE dalam tanah riolit pada kecepatan (a) 1G dan (b) 25G.

signifikan. Pada 90 menit kecepatan secara vertikal dan horizontal masing- masing adalah 0,04 dan 0,26 $\mathrm{cm} /$ menit. Pergerakan TCE tidak mencapai ke dasar tanah pada menit ke-90.
Pada kecepatan 25G, kecepatan vertikal dan horizontal TCE pada satu detik adalah 0,50 dan 23,50 cm/detik. Pada empat detik pergerakan secara horizontal sudah mencapai kedua ujung kotak 
sampel sehingga kecepatan setelah waktu tersebut adalah nol manakala pergerakan secara vertikal belum mencapai dasar tanah. Kecepatan vertikal pada 60 detik adalah $0,07 \mathrm{~cm} /$ detik.

\section{Pengaruh gravitasi terhadap pergerakan TCE}

Fagerlund dkk. (2006) menyatakan bahwa gaya gravitasi adalah faktor yang berpengaruh kepada gerakan NAPL dalam tanah. Penambahan gaya gravitasi dilakukan dengan menggunakan sentrifug geoteknik sebagai permodelan fisik dimana penambahan gaya gravitasi dari 1 menjadi NG menyebabkan NAPL bergerak lebih cepat dan hal ini dapat digunakan untuk memperkirakan pergerakan NAPL pada waktu yang lebih panjang (Lo dkk., 2004).

Gaya sentrifugal dapat diubah dengan mengubah kecepatan angular dari sentrifug. Penambahan gaya sentrifugal maka secara langsung akan menambah gaya gravitasi pada sampel (Simons, 2010). Jika kecepatan sentrifug semakin tinggi maka gaya yang bertindak pada sampel akan semakin besar.

Hukum perbandingan Culligan-Hensley dan Savvidou (1995) menyimpulkan bahwa perbandingan model/prototaip untuk waktu adalah $\mathrm{N}^{2} / 1$ dimana $\mathrm{N}$ adalah gravitasi. Ujian Soga dkk. (2003) menghasilkan perbandingan yang sesuai dengan hukum ini. Ujian tersebut menggunakan sentrifug geoteknik dengan jejari 5 meter. Pada gaya 20G, pergerakan model menjadi 400 kali lebih cepat berbanding prototaip.

Jika mengikuti hukum perbandingan ini, maka pada gaya 25G seharusnya penelitian menghasilkan pergerakan 625 kali lebih cepat berbanding 1G. Hasil perbandingan pergerakan TCE dalam granit ditunjukkan oleh Gambar 5.

Pada penelitian didapatkan bahwa pada kecepatan 1G, panjang vertikal TCE 4,5 cm didapat pada menit ke-20 sementara pada kecepatan 25G, panjang vertikal $4,3 \mathrm{~cm}$ didapat pada detik ke-2. Hal ini berarti penambahan kecepatan gravitasi menjadi 25G menyebabkan pergerakan TCE menjadi lebih

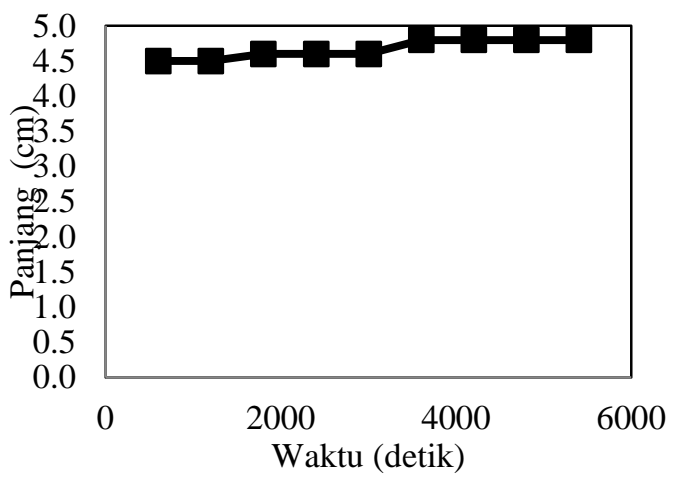

(a) kurang 600 kali lebih cepat berbanding 1G. Hal demikian mungkin disebabkan oleh ralat percobaan terutamanya adalah densitas yang berbeda antara percobaan pada kecepatan 1G dan 25G. Pada kecepatan 1G, setelah tanah dimasukkan, TCE langsung disuntik pada tanah manakala pada 25G, kotak sampel perlu diputar dahulu hingga kecepatan sentrifug mencapai 25G, setelah itu TCE baru disuntik pada tanah. Putaran sentrifug hingga kecepatan 25G menyebabkan tanah dalam kotak sampel lebih padat berbanding pada 1G.

Dengan menggunakan sentrifug geoteknik, maka panjang pergerakan pada jangka masa yang lama dapat diketahui dalam waktu yang singkat. Dari penelitian didapatkan bahwa dengan penambahan gaya gravitasi menjadi 25G menyebabkan pergerakan TCE menjadi lebih cepat lebih kurang 600 kali. Ini berarti jika antara keadaan tanah di lapangan dengan tanah dalam percobaan dalam keadaan yang sama, maka panjang pergerakan selama satu tahun (365 hari) dapat diketahui dalam 16,32 jam saja.

Prakiraan pergerakan polutan dapat dilakukan dengan dua cara yaitu permodelan matematika dan permodelan fisikal. Penelitian Setyaningrum (2010) adalah contoh permodelan matematika untuk pergerakan minyak disel (termasuk dalam golongan NAPL) pada akuifer di wilayah Yogyakarta. Penelitian ini menyimpulkan bahwa waktu tempuh partikel benzene dalam airtanah pada kondisi awal minimal 626,67 hari dan maksimum 1.880 hari. Penyebaran polutan selama 12 tahun mencapai 900 meter dari 1314 meter yang diperkirakan. Pemodelan fisikal dapat dilakukan salah satunya dengan sentrifug geoteknik.

Pengaruh sifat media terhadap pergerakan TCE

Pantazidou dan Liu (2008) menyatakan bahwa struktur tanah adalah faktor yang berpengaruh besar pada pergerakan NAPL. Plaster (2009) menambahkan bahwa selain struktur, tekstur tanah juga menjadi penentu pada perhubungan pori tanah dan karena itu berpengaruh terhadap kemampuan

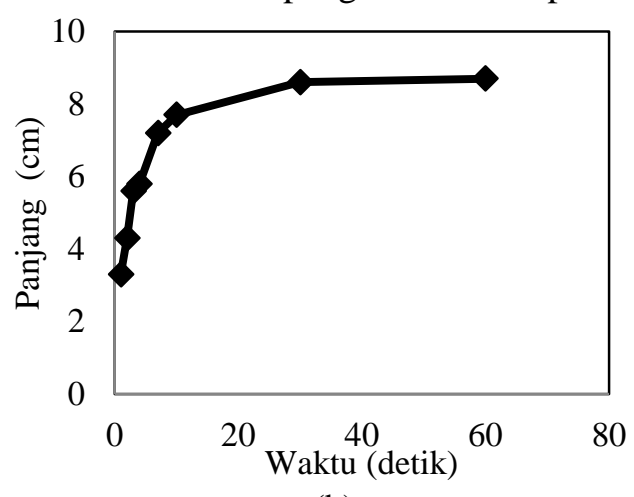

(b)

Gambar 5. Perbandingan pergerakan TCE dalam tanah granit pada 1G (a) dan 25G (b) 


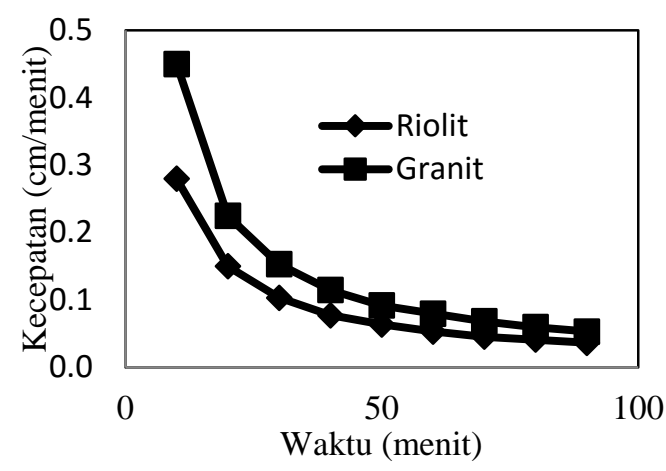

(a)

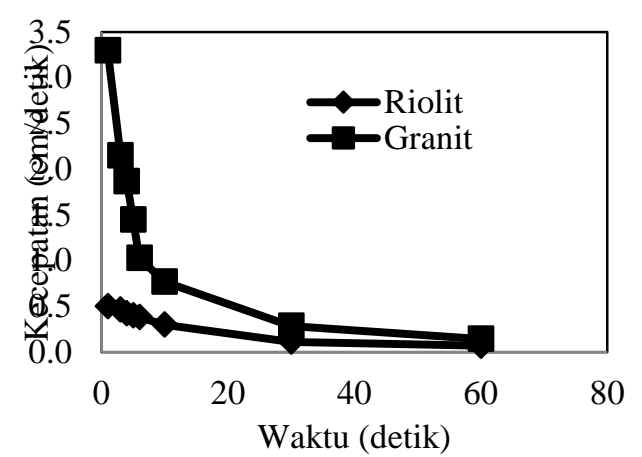

(b)

Gambar 6. Pergerakan vertikal TCE dalam media tanah pada kecepatan 1G (a) dan 25G (b)

tanah dalam mengangkut NAPL. Hal ini didukung oleh Bradford dkk. (1998) yang menyatakan bahwa pergerakan dan penjerapan NAPL pada akuifer diyakini dikontrol oleh keragaman fisik tanah, yang mana pendapat ini berdasarkan pada andaian bahwa sifat permeabilitas dan kapilari ditentukan oleh tekstur tanah.

Kecepatan pergerakan vertikal TCE dalam tanah granit dan riolit pada kecepatan 1G dan 25G dapat dilihat pada Gambar 6. Hasil penelitian menunjukkan bahwa pada gaya 1 dan 25G, pergerakan vertikal TCE paling cepat adalah dalam tanah granit. Hal ini disebabkan karena tekstur tanah riolit memiliki nilai persentase jumlah lanau yang besar yaitu 72,5-75,5\% berbanding 14-19\% pada granit. Persentase butir pasir pada tanah riolit juga lebih sedikit berbanding tanah granit yaitu 8-11\% berbanding 55-63\%. Butir-butir yang kecil pada riolit menghambat pergerakan TCE. Ini dibuktikan juga riolit mempunyai nilai KPK yang besar yaitu yang 2,7-11 berbanding 0,6-0,9 pada granit.

Hasil ujian ini sama dengan ujian yang dilakukan oleh Lo dkk. (2004) di mana telah menguji pergerakan LNAPL dengan menggunakan sentrifug geoteknik. Ujian menggunakan tanah jenis Completely Decomposed Granite (CDG) dan pasir halus dimana tanah CDG secara umum lebih kasar berbanding pasir halus. Ujian ini mendapatkan bahwa pasir halus lebih banyak dapat menahan LNAPL daripada tanah CDG.

Notodarmojo (2005) mengatakan bahwa polutan yang berada dalam tanah selalu dalam kondisi dinamis yaitu berinteraksi dengan partikel tanah atau mengalami tranformasi sampai terjadi kesetimbangan. Selain itu larutan tanah dapat bergerak sesuai dengan energi yang dimilikinya, ke arah dimana energinya lebih rendah. Fenomena yang penting mengenai pergerakan polutan dalam tanah adalah adveksi, dispersi hidrodinamik dan retardasi.

Pergerakan karena adveksi merupakan proses fisik dimana air sebagai medium, bergerak sambil membawa polutan yang berada didalamnya. Pergerakan karena dispersi hidrodinamik merupakan pergerakan massa akibat difusi polutan, karena gradien konsentrasi yang mengakibatkan gerak Brown serta mekanisme dispersi. Hal ini terjadi karena ketidakteraturan alur atau lintasan air yang melalui pori tanah dan retardasi merupakan fenomena yang menunjukkan perubahan jumlah dari polutan selama proses pergerakan akibat reaksi antara polutan dengan media tanah, yang memberikan efek seolah-olah gerakan polutan menjadi terhambat

\section{KESIMPULAN}

Sifat pergerakan TCE dalam tanah riolit dan granit pada kecepatan 1G dan 25G adalah TCE akan masuk langsung secara vertikal dan horizontal dalam tanah hingga ke dasar tanah. Pergerakan TCE akan terhambat pada tanah yang banyak mengandung partikel berukuran kecil. Pergerakan TCE secara vertikal pada kecepatan $1 \mathrm{G}$ dan 25G dalam tanah granit lebih cepat daripada tanah riolit. Pergerakan TCE dalam tanah kering dipengaruhi oleh sifat tanah terutama ukuran butir tanah. Sentrifug geoteknik dapat digunakan sebagai pemodelan fisikal untuk memprediksi pergerakan TCE pada masa yang akan datang.

\section{UCAPAN TERIMAKASIH}

Terima kasih diucapkan kepada penanggungjawab makmal Geotechnical Centrifuge Universiti Kebangsaan Malaysia (UKM) Prof. Wan Zuhairi Wan Yaacob atas izinnya menggunakan sentrifug geoteknik UKM.

\section{DAFTAR PUSTAKA}

Anonim, 1985. Laboratory Manual. McGill University, Montreal. 
Anonim, 2001. Handbook of Public Water System. John Wiley and Sons, Inc., New York.

Anonim, 2010. Parkinson's Institute Disease and Clinical Centre. http://www.thepi.org/

Anonim, 2011. Laboratory Soils Testing. U.S. army corps of engineers, www.vulcanhammer.net.

Barth, G.B., Illangasekare, T.H., dan Rajaram, H., 2003. The Effect of Entrapped Nonaqueous Phase Iiquids on Tracer Transport in Heterogeneous Porous Media: Laboratory Experiments at The Intermediate Scale. Journal of Contaminant Hydrology, 67:247268.

Bradford, S.A., Abriola, L.M., dan Rathfelder, K.M., 1998. Flow and Entrapment of Dense Nonaqueous Phase Liquids in Physically and Chemically Heterogeneous Aquifer Formations. Advances in Water Resources, 22:117-132.

Ca'-Piro, N.L., Stafford, B.P., Rixey, W.G., Bedient, P.B., Pedro J.J., dan Alvarez, P.J.J., 2007. Fuel-Grade Ethanol Transport and Impacts to Groundwater in A Pilot-Scale Aquifer Tank. Water Research, 41:656-664.

Culligan-Hensley, P.J., dan Savvidou, C., 1995. Environmental Geomechanics and Transport Processes, dalam Taylor, R.N. (Ed). Geotechnical Centrifuge Technology. Blackie Academic \& Professional, London.

Fagerlund, F.F., Niemi, A., dan Ode'N.M., 2006. Comparison of Relative Permeability-Fluid Saturation-Capillary Pressure Relations in The Modelling of Non-Aqueous Phase Liquid Infiltration in Variably Saturated Layered Media. Advances in Water Resources, 29:1705-1730.

Hu, L.M., Irene, M.C.L., dan Meegoda, J.N., 2006. Centrifuge Testing of NAPL Migration and Soil Vapor Extraction for Soil Remediation. Practice Periodical of Hazardous, Toxic, and Radioactive Waste Management, 10(1):33-39.

Kumar, P.R., 2006. An Experimental Methodology for Monitoring Contaminant Transport through Geotechnical Centrifuge Models. Environmental Monitoring and Assessment, 117:215-233.

Lo, I.M.C., Hu, L.M. dan Meegoda, J.N., 2004. Centrifuge Modeling of Light Nonaqueous Phase Liquids Transport in Unsaturated Soils. Journal of Geotechnical and Environmental Engineering, 130(5):535-539.

Luciano, A., Viotti, P., dan Papini, M.P., 2010. Laboratory Investigation of DNAPL Migration in Porous Media. Journal of Hazardous Material, 176:1006-1017.
Ma, C., Wu, Y., dan Sun, C., 2007. Adsorption Characteristic of Perchloroethylene in Natural Sandy Materials with Low Organic Carbon Content. Environment Geology, 52:15111519.

Notodarmojo, S., 2005. Pencemaran Tanah dan Air Tanah. Penerbit ITB, Bandung.

Pantazidou, M., dan Liu, K., 2008. DNAPL Distribution in the Source Zone: Effect of Soil Structure and Uncertainty Reduction with Increased Sampling Density. Journal of Contaminant Hydrology, 96:169-186.

Plaster, E.J., 2009. Soil Science and Management. $5^{\text {th }}$ Edition. Delmar Cengage Learning, New York.

Simons, J., 2010. Improving Techniques and Practices on The Geotechnical Centrifuge at The University of Nottingham. Thesis, Civil Engineering, University of Nottingham.

Sleep, B.E., Durant, N.D., Faust, C.R., Guarnaccia, J.G., Harkness, M.R., Parker, J.C., dan Sehayek, L., 2003. Modeling Fate and Transport of Chlorinated Organic Compounds in the Subsurface dalam Zheng, C., et al. Contaminated Ground Water and Sediment Modeling for Management and Remediation. CRC Press, New York.

Soga, K., Kawabarata, J., Kechavarzi, C., Coumoulos, H., dan Waduga, W.A.P., 2003. Centrifuge Modelling of Nonaqueous Phase Liquid Movement and Entrapment in Unsaturated Layered Soils. Journal of Geotechnical And Geoenvironmental Engineering, 129(2):173-182.

Setyaningrum, W., 2010. Model Pergerakan Bahan Pencemar Minyak Disel pada Akuifer Batupasir Formasi Volkanik Merapi Muda. Jurnal Geografi, 7(2):75-87.

Setyoningrum, H.M., Hadisusanto, S., dan Tukidal, Y., 2014. Kandungan Cadmium (Cd) pada Tanah dan Cacing Tanah di TPAS Piyungan, Bantul, Daerah Istimewa Yogyakarta. Jurnal Manusia dan Lingkungan, 21(2):149-155.

Wilson, D.J., dan Clarke, A.N., 2004. Hazardous Waste Site Soil Remediation. Marcel Dekker Inc., New York.

Zhang, C., Wu, L., Luo, Y., Zhang, H., dan Christiec, P., 2008. Identifying Sources of Soil Inorganic Pollutants on A Regional Scale Using A Multivariate Statistical Approach: Role of Pollutant Migration and Soil Physicochemical Properties. Environmental Pollution, 151(3):470-476. 